\title{
U.S. Provincial Reconstruction Teams in Afghanistan: Best Practices and Recommended Improvements
}

\author{
Lieutenant Colonel Todd Brown
}

The post 9/11 counter-terrorism efforts in Afghanistan were swift and achieved impressive results in a relatively short period of time, but the follow-on task of building a democratic, secure, and sustainable Islamic Republic was far more daunting. In spite of this complex and resource-intensive task, the U.S.-led Coalition and International Security Assistance Force (ISAF) have achieved much over the past six years. The Afghan people forged a new constitution and successfully conducted its first ever democratic Presidential and Parliamentary elections. With international assistance, the nascent Afghanistan government devised a national development strategy, which through the Bonn and London pacts is now tied to clear and measurable benchmarks. On the security front, the Afghan National Army is 50,000 strong and growing. More importantly, these forces are now effectively fighting alongside Coalition forces. Afghan national health care and education capacity has significantly increased, with basic health care available to at least $80 \%$ of the population and basic education available to some 5 million Afghan children — a $500 \%$ increase from $2001{ }^{1}$

Notwithstanding these extraordinary successes, Afghanistan is still engulfed in what is now characterized as a counter-insurgency fight pitting ISAF forces against Taliban and other insurgents supported by foreign fighters. ${ }^{2}$ ISAF numbers some 41,700 troops, which includes some 15,000 U.S. soldiers, sailors, airmen, and marines. ${ }^{3}$ In the counter-insurgency campaign, the desired end state is to create the conditions of security and stability that will allow the Islamic Republic of Afghanistan (IRoA) to carry out its reconstruction and development plan and

Lieutenant Colonel (P) Todd D. Brown is a U.S. Army Eurasian Foreign Area Officer (FAO) and is currently serving on the faculty of the George C. Marshall European Center for Security Studies. From July 2006-April 2007, he served in Afghanistan as a staff officer and as the Nuristan Provincial Reconstruction Team Commander. His other foreign area officer assignments include service as a Military Attaché in both Ukraine and Uzbekistan and Director of the U.S. Army Eurasian FAO training program.

1 Donald Rumsfeld, "State of Afghanistan, Five Years Later," Washington Post (7 October 2006), A23.

2 Joseph D. Celeski, “Operationalizing COIN," Joint Special Operations University Report 5:2 (September 2005): 64.

3 ISAF slide of forces deployed in Afghanistan as of 5 December 2007, available at: www.nato.int/isaf/docu/epub/pdf/isaf_placemat.pdf. 
transform itself into a stable democracy. ${ }^{4}$ Critical to this effort is ISAF's ability to successfully meld military kinetic and non-kinetic operations and activities to achieve the desired end state.

Since 2002, the U.S.-led Coalition - and now the NATO-led ISAF-has employed provincial reconstruction teams (PRTs) as its primary conduit for non-kinetic operations. Typical PRT activities include mentoring district and provincial government leaders, conducting infrastructure development projects, and coordinating agricultural and health sector assistance. PRTs are stability operations tools that provide a mechanism to extend the reach of the government to the local level and provide a path to transfer security and reconstruction functions to fledgling democratic governments. Currently, there are twenty-five PRTs operating in Afghanistan (twelve U.S. and thirteen non-U.S.) This article will discuss the U.S. PRT mission and organization, best practices and challenges, and finally offer some recommendations to improve on PRT effectiveness in the counter-insurgency environment of Afghanistan as well as in the broader global context.

\section{The PRT Organization: Do We Have the Right Model?}

The PRT is an ad hoc joint interagency military-led organization (U.S.-Afghan model). The framework of a typical U.S. PRT organization is provided in Figure 1. The basic elements are a command and control cell, a civil affairs/engineering cell, a police training and assistance team (PTAT), force protection platoon, and the standard logistic support elements. The command and control cell is augmented with representatives from the Department of State (DoS), U.S. Agency for International Development (USAID), and in some instances the Department of Agriculture (USDA). Each PRT is also assigned two or more civilian police mentors. These mentors are contracted through the DoS and provide law enforcement capacity building capability at the district and provincial levels and compliment the effort of the PRT PTAT.

The mission of this approximately 100-person organization is to extend the authority of the IRoA in order to facilitate the establishment of a stable and secure environment and enable security sector reform and reconstruction efforts. Simply put, the PRT is in the business of building governance, economic, and security capacity at the provincial and district levels. Almost all U.S. PRTs are under the direct command of a U.S. brigade combat team commander, who is assigned to an ISAF regional command; in the majority of instances, this is Regional Command East (see Figure 2 for PRT Command and Control). To accomplish its mission, the PRTs work very closely with the Provincial governor, the provincial development committee, and the provincial security committee. The latter two bodies are at

4 Detailed information on the mission and role of ISAF in Afghanistan is available at: www.nato.int/issues/isaf/index.html and www.nato.int/issues/afghanistan/index.html. 


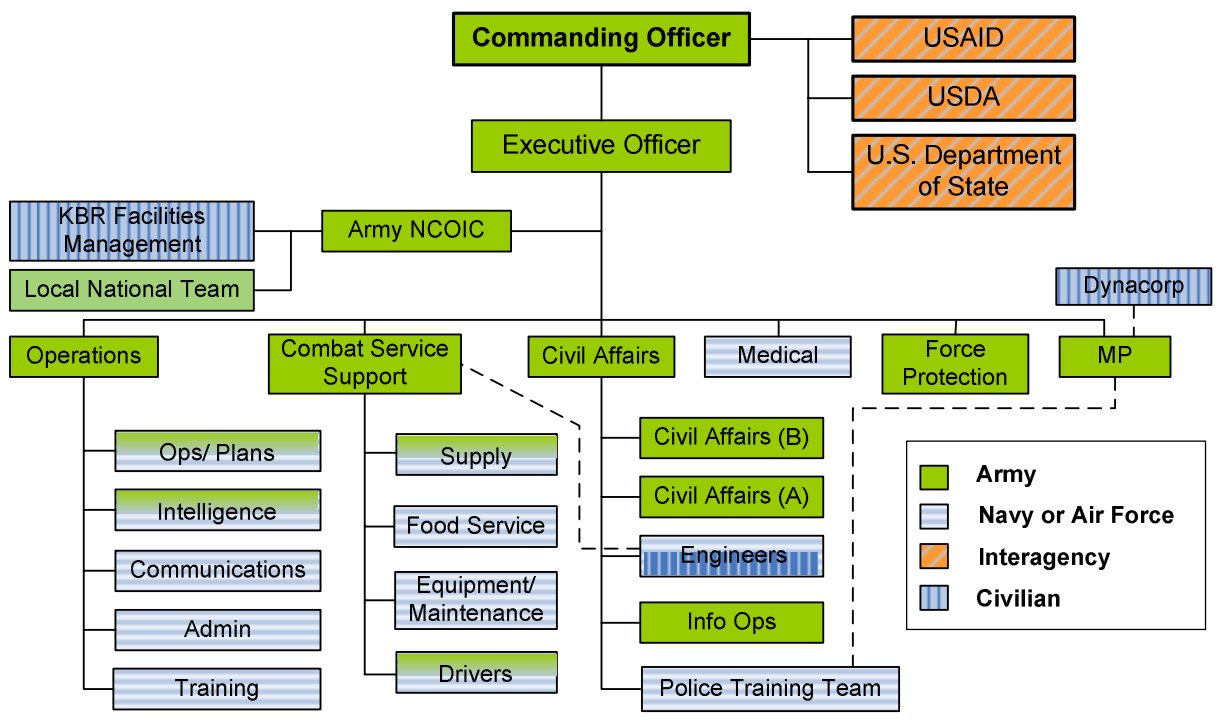

\section{PRT Joint / Interagency Command of up to 150 people}

Figure 1: Organization of a Typical U.S. PRT

varying levels of development but provide the best mechanisms for coordinating reconstruction and security sector efforts at the provincial level. Thus, while building governance and security capacity, the PRTs also serve as the focal linkage of ISAF non-kinetic activities at the provincial and district levels of government.

Although the PRTs are organized to specifically address issues related to reconstruction and development, the actual level of experience of assigned personnel and a lack of proper training often constrain the overall tactical and operational effects of the teams. PRTs are assigned a complex and demanding mission, yet the experience level of assigned personnel in critical leadership positions does not reflect the importance and complexity of the PRTs' efforts. Although PRT Commanders are operationally experienced Naval, Army, and Air Force officers, the supporting staffs are generally individual augmentees with little experience in assigned staff positions. In the PRT with which I worked, the operations officer was a newly promoted captain who had not yet commanded a company, much less planned complex non-kinetic operations. Another example is PRT civil affairs officers. The vast majority of the civil affairs personnel assigned to PRTs are not experienced in civil affairs. Every civil affairs officer was a reservist whose only civil affairs experience was the standard civil affairs course provided at Fort Bragg, 


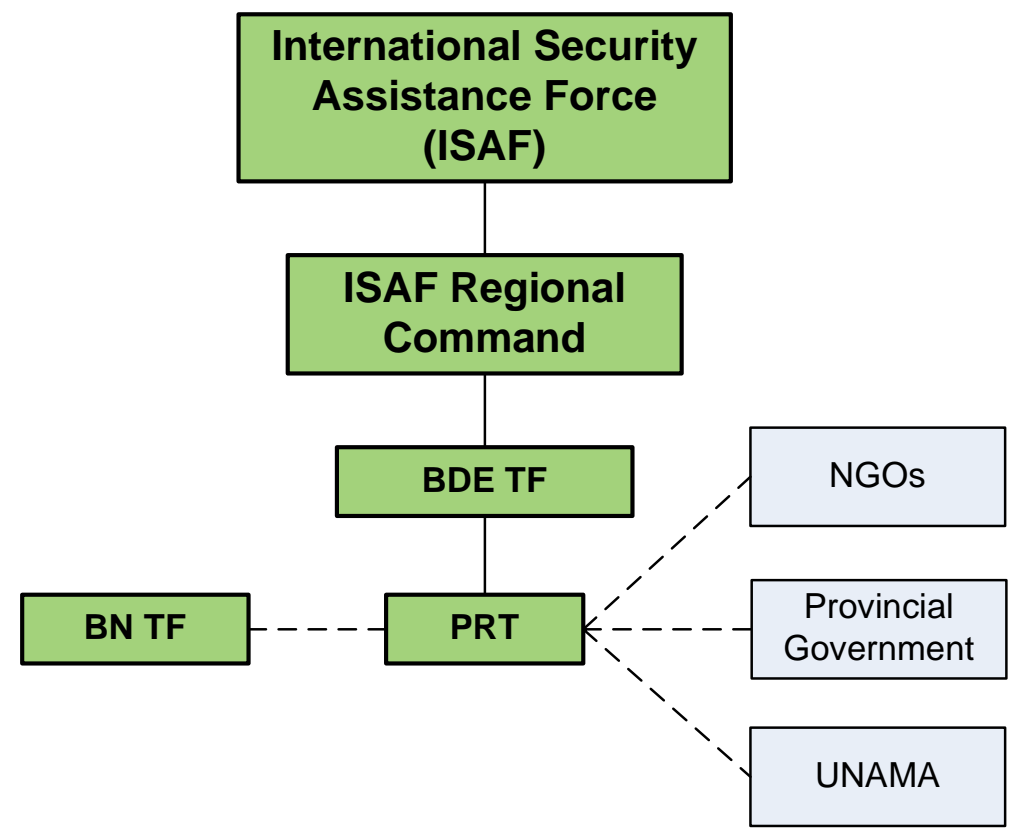

Figure 2: PRT Command and Control Structure

North Carolina prior to deployment. Other PRTs had staff with similar levels of civil affairs experience. Not one U.S. PRT is manned with experienced active duty civil affairs personnel. The PRT engineer cell is manned with military engineers who in many cases are not professionally qualified as building or road construction engineers. The recent addition of Army Corps of Engineers professional engineers has provided much-needed expertise to oversee the myriad of PRT construction efforts, from roads and bridges to schools and clinics.

Perhaps most glaringly, with few exceptions, PRTs do not have a military or civilian member with regional- or country-specific cultural and language skills. Although, each PRT did have assigned interpreters who assisted the team in negotiating the complex cultural environment of Afghanistan, trained cultural experts, like Army Foreign Area Officers, would contribute immeasurably to the planning and execution of PRT activities. Current and past PRT personnel performed magnificently in spite of the general lack of experience (and sometimes skills). If the PRT is the primary non-kinetic weapon in counter-insurgency efforts, then in order to maximize the PRTs' tactical and operational effectiveness our leaders need to ensure that these organizations are equipped with experienced officers, noncommissioned officers, and civilians with the right skill sets. 
Another aspect of the U.S. PRT organization that needs review is its "cookiecutter model" - the assumption that the same type of PRT is best suited to all cases. The reality is that the provinces in which the PRTs operate are diverse in size and terrain, population, ethnicity, level of development, and security environment. Just as military commanders tailor combat forces for specific missions, so too should commanders consider tailoring PRTs to fulfill non-kinetic missions. The PRTs are currently filled with a mix of active duty and reserve individual augmentees. In Army civil affairs doctrine, there is a small team of experts called the Civil Affairs Planning Team B (CAPT B). This small team of five to ten members is made up of functional experts who can interface with host nation government officials to share knowledge and experience - in short, to help build governance capacity. These could be functional experts in the areas of education, finance, banking, construction, and others, based on the province's specific requirements. Having access to CAPT Bs would enhance the PRTs' ability to build capacity across a number of functional areas at the provincial level. Screening reservist PRT augmentees for functional expertise could provide a basis for several CAPT Bs, which the maneuver commander could use to weight his non-kinetic PRT efforts in a particular province.

Some provinces, on the other hand, present a more challenging security environment, and the Task Force Commander may consider shifting PRT organic force protection and police training and assistance team (PTAT) assets to these less secure areas. Task-organizing PRTs to focus additional non-kinetic resources in the Task Force Commander's main effort and utilizing the principle of economy of force may produce more effective non-kinetic effects than the application of a one-size-fits-all approach.

Similarly, other U.S. government agencies should consider developing modular teams that can contribute to the PRTs based on specific requirements at the provincial and regional levels. Currently, only three members of the interagency community make contributions to the PRTs (DoS, USAID, USDA). However, in almost every province there is a desperate need for representatives from the Justice Department, the Department of Education, and even the Department of Health \& Human Services. These functional experts would provide additional capability to the PRT in building human capacity and functional government systems at the provincial and regional levels.

I use the term modular because every situation is unique and will require a different mix of functional expertise to address the varying development and reconstruction requirements. As requirements are identified, the idea would be to draw on U.S. government modules and plug them into identified PRT requirements on the ground. Each U.S. government agency should identify, fund, and integrate these modular teams into regular military mission training exercises at the Army's Joint Readiness Training Center, National Training Center, and the Joint Multi- 
National Training Center in Germany. These training opportunities will provide potential interagency team members with the specific knowledge required to operate in a stability operations environment, and will also build the institutional and professional relationships required for achieving synergy in the field.

Another potential resource to consider in building PRT capacity is tapping into the vast experience and expertise of the American public. If our government agencies are ill equipped or trained to fill critical needs in stability operations, then a possible alternative is to out-source to the public and/or private sectors. If the PRTs are lacking expertise in agriculture, education, public administration, or health care administration, there are thousands of Americans with this type of knowledge who can be recruited to participate in stability operations. This serves two functions. First, it increases the PRT's capabilities. Second, and more importantly, on the strategic level it provides an opportunity for the American public to contribute in a meaningful way to the U.S. war effort.

The selection of PRT Commanders must be carefully considered, ensuring that these officers have the right skill set to operate effectively in a joint interagency multinational stability operations environment. The leadership of the PRT organization is critical to its success. With the exception of only one PRT in Afghanistan, all are commanded by a military officer. The commander or civilian equivalent is critical in forming a functional and effective interagency team. A recent interagency PRT assessment suggested that PRT commanders be selected from former proven maneuver battalion commanders. ${ }^{5}$ Although such officers are talented and well qualified, I would submit that former battalion, ship, and squadron commanders are not the best qualified to lead a PRT. A better choice is an experienced foreign affairs or civil affairs officer, who typically would have served several assignments in U.S. Embassies and is a cultural and linguistic expert. The Navy and Air Force should consider those officers from its foreign area officer pools. These officers are trained soldier-diplomats, culturally astute, and have had far more exposure to the interagency process than the majority of maneuver battalion commanders. Understanding the roles of the interagency PRT members and the valuable skills and program resources they bring to the fight-knowledge that most FAOs and CA officers possess - would go a long way toward building an effective PRT interagency team. At a minimum, future training for PRT commanders

See United States Agency for International Development, "Provincial Reconstruction Teams in Afghanistan: An Interagency Assessment" (5 April 2006), available at: http://pdf.dec.org/pdf_docs/Pnadg252.pdf. See also the website of the U.S. Department of State, Office of the Coordinator for Stabilization and Reconstruction, at: www.state.gov/s/crs/index.cfm? fuseaction=public.display\&shortcut $=$ eh52\&cfid $=63143 \&$ cftoken $=96050896$. 
must include a large dose of the interagency process and a thorough grounding in the specific roles and missions of the interagency PRT members.

The PRTs fulfill an important function in stability operations. As the organization continues to evolve, it is important that our leaders-both military and civilian-provide the PRTs with adequate resources to achieve their reconstruction and development goals. Building PRTs through modularity, out-sourcing, realistic training, and selection of our most capable leaders provides the theater commander with his most powerful weapon in the counter-insurgency effort. In the next section, I will describe several PRT best practices and offer a few recommendations for improved coordination and synchronization of PRT efforts.

\section{PRT Best Practices}

One of the more important aspects of the current PRT organization is its civilmilitary structure, meaning that the addition of civilian professionals from the State Department and other agencies is a key component of the PRT model. Organizing the PRT civil-military leaders into an executive committee provides an excellent decision-making and coordination apparatus. A typical committee might consist of the PRT Commander, State Department and USAID representatives, a senior civil affairs officer, and the operations officer. Ideally, this group would consult daily to assess current activities and discuss future operations. This format allows senior PRT members to discuss various approaches to PRT activities and provides the opportunity to leverage all available resources to achieve a desired effect. A sub-set of the executive committee meeting is the PRT development project review working group. This group is typically led by the PRT Commander or the USAID field project officer. The objective of this interagency meeting is to properly vet development projects so that each project has community and provincial government support, is sustainable, and is linked as much as possible to the national government's long-term development strategy. Without these interagency forums, which provide opportunities to share opinions and compare approaches (and which in most cases achieve consensus on PRT activities), PRT civilian agency members become marginalized, and opportunities for synergy in reconstruction and development efforts are missed. ${ }^{6}$

PRTs positioned in or near provincial centers are the best available tool to influence the development of provincial governance and reconstruction capacity. Indeed, one of the more important objectives of the PRT is to build these capacities at the provincial level. The vehicle for this is the provincial development

6 Specific examples on best practices were compiled while I served as a PRT LNO at both CFC-A and at JTF Spartan ( $3^{\text {rd }}$ Independent Brigade Combat Team, $10^{\text {th }}$ Mountain Division) from July 2006 to April 2007. 
council (PDC). ${ }^{7}$ The United Nation Assistance Mission-Afghanistan (UNAMA) is responsible for coordinating international assistance efforts, and takes the lead on developing the skills and capacity of the provincial development council. In spite of this mandate, UNAMA has a very limited presence outside of Kabul, and therefore has had little effect on provincial development councils.

On the other hand, several PRTs have had a profound impact on energizing and building real development capacity at the provincial level. The interagency PRTs, using the UNAMA/IRoA vision for PDCs, have directly engaged key provincial leaders to become involved in regular provincial development meetings and working groups. In Paktika province, the Sharana PRT conducted a PDC training session with key provincial government leaders and continued to coach and mentor the provincial governor to form a committee on provincial development. The governor now receives reports from relevant line ministry representatives (Ministry of Economy, Ministry of Reconstruction and Rural Development, Ministry of Education, and others) and provides specific guidance and follow-up assignments. These committee meetings provide the provincial leadership the venue to develop the priorities and specific projects for a basic provincial development plan.

To complement the provincial development meetings, the Sharana PRT conducted one-on-one capacity building sessions using the organic expertise and talents of the PRT. One Sharana PRT reservist had a banking and finance background and, coupled with the State Department and USAID representatives, provided instruction and advice to the chief of the provincial economic department. Because the PRTs are located in or near the provincial capital and possess development expertise, they are uniquely suited to mentor, coach, and train provincial leaders on the basics of how to develop a coordinated and synchronized provincial development plan. The provincial teams are able to have much more success in this regard than other organizations based out of Kabul, who have infrequent contact with provincial government leaders.

As mentioned above, the PRT's mission is focused on the execution of non-kinetic activities. However, to achieve the greatest benefit in support of higher headquarters' overall mission, the activities of the PRT must be closely synchronized with maneuver commanders who de facto control the battle space. PRT commanders who are co-located with their maneuver counterparts tend to have

The provincial development committee concept was developed in 2004 and is an extension of the UNAMA-supported provincial coordination body. I received this information and other background on UNAMA support of PDCs from the UNAMA-produced document "The Provincial Development Council Fact Sheet" and a briefing entitled "Provincial Development Committees - Need for Strengthening," obtained in meetings with UNAMA representatives on 6 November 2006 at FOB Salerno. 
much better success at coordinating and synchronizing kinetic and non-kinetic activities within the shared battle space. PRT Khost and its maneuver counterpart, TF 4-25, TF Spartan (3rd Brigade Combat Team, $10^{\text {th }}$ Mountain Division) used a weekly synchronization meeting to align and coordinate activities. Typical topics of discussion were synchronization and leveraging of resources to ensure coverage of key leader engagements throughout the province, discussion of specific kinetic activities, and strategic planning on the use of PRT resources to mitigate potential negative consequences with the local population. A good example of the latter type of coordination is the Jalalabad PRT's practice of assisting with the re-integration of former detainees into the community. The PRT leadership worked closely with maneuver elements affecting the release of a detainee. The PRT would provide the detainee with a supply of humanitarian goods for the detainee's family, as well as facilitate the delivery of the detainee to community leaders.

Another important aspect of PRT-maneuver force coordination meetings was the opportunity for leaders to "sync" key messages for upcoming meetings and to share feedback from recent key leader engagements. This ensures that PRT and maneuver commanders understand and deliver the same messages, on the same themes, and are aware of the most current host nation government issues and leadership dynamics. Where possible, PRTs should be located with maneuver elements that are operating in the same battle space to facilitate the establishment of effective coordination and synchronization linkages.

Ensuring community buy-in to construction projects is critical to mitigating associated security risks. In some areas of southern and eastern Afghanistan, the security situation poses challenges to development and reconstruction efforts. The Asadabad PRT used an effective technique that significantly mitigated the risks to both the PRT and contractors involved in various reconstruction projects. Before initiating any project, the PRT Commander would meet with the community elders located in the area of the proposed project. In this meeting, or shura, the commander would re-confirm that the village elders desired the project and, more importantly, that the community elders would guarantee the security of the contractors and PRT members involved in the construction. Often a formal agreement was signed, with the elders affixing their "thumb print" to a declaration of support for the project. This proved to be a powerful tool in a culture where honor is so highly regarded. With this agreement, the PRT was able to ensure community buyin to the project and hold the village elders accountable for project security.

Integrating Afghan security forces into PRT activities builds the capacity of the force and provides a powerful example of a functioning government to the local population. A great example of a well-executed joint and combined PRT activity is the Jalalabad PRT's execution of a very sophisticated medical civil affairs project (MEDCAP) in the district of Dor Baba, Nangahar Province in October 2006. PRTs often use MEDCAPs in providing medical and veterinary assistance to the 
Afghan population. Normally, humanitarian assistance is also distributed to the populace in conjunction with the medical services. In this case, the Jalalabad PRT coordinated the participation of the Afghan National Army (ANA), Afghan National Police (ANP), French Special Forces, and U.S. military medical teams in the execution of the MEDCAP. To provide security for the event, the PRT employed ANA, ANP, French Special Forces, and U.S. military police in a series of static checkpoints and joint patrols in the MEDCAP area. The ANA and ANP were also used to distribute the humanitarian assistance. Simultaneously, the U.S. medical teams provided assistance to some 3,000 Afghans and over 500 animals. In this example, the medical needs of the people of the Dor Baba district were met. But, more importantly, this aid was delivered through and with the direct involvement of Afghan security forces, who both provided security and assisted in the delivery of the medical and humanitarian aid. Not to be overlooked was the dual purpose of building the security capacity of the Afghan security forces, as the French Special Forces and U.S. military police partnered with the ANA and ANP during this event. Additionally, during conduct of patrols throughout the district, PRT members along with Afghan security force members were able to conduct a series of key leader engagements facilitating the connection of the population with the Afghanistan authorities. Although reported as a MEDCAP, the Jalalabad PRT was able to plan and coordinate this activity with host nation and other Coalition forces to achieve positive effects beyond simply providing medical assistance.

\section{PRT Links to NGOs and Kabul}

In most PRTs, no one is tasked to establish liaison with non-governmental organizations working in the battle space. As a result, contact and coordination with NGOs is sporadic. In Afghanistan, the UNAMA (in conjunction with the IRoA) is tasked with the responsibility to register and monitor NGOs contributing to the reconstruction and development effort. Unfortunately, the relatively small number of UNAMA field offices outside of Kabul limits its ability to assist in coordinating NGO efforts. In some PRTs, there are efforts to make contact with NGOs through a monthly meeting with UNAMA representatives; however, these ad hoc efforts are limited in scope and effectiveness. PRTs, through the provincial government, should organize regular NGO meetings to coordinate, synchronize, and leverage resources and activities. The logical PRT members to coordinate this effort are the DoS and USAID representatives. Some NGOs are reluctant to associate with a military organization, but the civilian element of the PRT coupled with a neutral meeting location may provide an acceptable alternative. Assisting the provincial governments in attracting NGOs and then working and sharing information with them in a regular forum will create added synergy in provincial reconstruction and development. Building this bridge with NGOs is important, since the presences of a vibrant and effective NGO network committed to the long-term development of 
Afghanistan sets some of the conditions for the eventual downsizing and closure of PRTs.

Many of the issues that PRTs coordinate at the provincial level have linkages to the central government. U.S. PRTs communicate these issues through the Brigade Task Force (BDE TF) and Joint Task Force (JTF) command channels. Many of the requests for information and clarification require coordination with multiple U.S. government agencies and military commands located in Kabul. As currently configured, ISAF has a PRT policy cell, and until recently, CFC-A had a PRT policy cell as well. In addition, the U.S. Embassy has a PRT policy representative, and U.S. AID has a PRT policy officer, all working PRT issues for their respective agency/command. It would make sense to create a U.S interagency PRT action group for all PRT-related issues. The action group would consist of all members mentioned above, as well as a representative from the Combined Security Transition Command-Afghanistan (CSTC-A) and the U.S. Army Corps of Engineers' Afghanistan Engineering District (AED). The BDE TF or JTF would then have a one-stop shop for all PRT issues requiring national-level attention. Additionally, the action group concept would facilitate the sharing of PRT information and more rapid interagency coordination. The best location for this office would be at the U.S. Embassy. Some may argue that this cell is better positioned at the U.S. JTF level. However, the JTF is located at Bagram airfield; this site's physical separation from Kabul would hinder face-to-face coordination with U.S. assistance program coordinators and, more importantly, with IRoA government ministries, all of which are located in Kabul. Streamlining PRT efforts at the national level through a PRT interagency action group provides transparency on all PRT issues and enhances the United States' ability to address key reconstruction and development issues.

\section{Conclusion}

U.S. PRTs in Afghanistan are making a difference. In FY2006, Regional Command East U.S. PRTs administered over USD 25 million in assistance. ${ }^{8}$ Projects ranged from the construction of new schools, district government centers, and roads to mosque refurbishment, micro-hydro power generation, canal repairs, and health clinic repairs. In addition to the reconstruction assistance, PRTs distributed several million dollars of humanitarian aid to remote villages suffering from droughts, flash flooding, and extreme poverty. Not measurable in dollars but arguably more important, PRTs also built human capacity through daily interaction with provincial and district leaders, provincial and district security forces, and continue to provide a stabilizing presence in remote northeastern areas of Afghanistan.

8 Figures obtained from TF Spartan Civil Military Affairs Cell, October 2006. 
The PRT model continues to evolve, and some of the best practices shared in this article are intended to highlight some recent successes and contribute in a meaningful way to the continued development of PRT tactics, techniques, and procedures as well as policy. Selecting the best and brightest to form a PRT interagency team is critical to the success of a PRT. The Department of State, the U.S. Agency for International Development, as well as the Department of Defense need to take this task seriously. Military leaders should strive to select experienced foreign area officers and civil affairs officers with a strong interagency background as PRT Commanders.

Building provincial reconstruction and development capacity is another critical PRT task. Teaching, mentoring, and coaching provincial, district, and community leaders about the provincial development process and obtaining buy-in and ownership for projects is key to the eventual draw-down and closure of PRTs. Along with building host nation development and reconstruction capacity, PRTs should strive to build a relationship with NGOs active in the region, synchronizing activities and leveraging resources for maximum benefits. PRTs and maneuver units sharing the same battle space need to develop communication links to properly coordinate kinetic and non-kinetic activities. Without a regular mechanism to share information and coordinate activities, opportunities to achieve synergy in the battle space will be missed. JTF Commanders need to consider the PRTs as a nonkinetic maneuver unit and task-organize the teams appropriately to achieve the desired effects in the battle space. Lastly, creating an interagency PRT action group co-located at the U.S. Embassy in Kabul would go a long way toward coordinating U.S. PRT efforts at the national level.

U.S. PRTs are on track in Afghanistan. The Department of Defense along with other interagency team members should continue to seek improvements to its PRT training efforts, expanding on the PRT seminar at the Department of Defense's Near Eastern and South Asia Studies Center. Lessons learned should be incorporated into maneuver unit rotations at the military training centers, and deploying PRTs should participate in these training rotations to acquire and practice the skills required to operate effectively in an environment characterized by strong insurgent activity. Finally, we should continue to share our PRT experiences with friends and allies so that we may encourage them to develop similar capacities for the long war ahead. 
WINTER 2007

\section{Bibliography}

Briefing entitled "Provincial Development Committees - Need for Strengthening". FOB Salerno: meetings with UNAMA representatives, 2006.

Celeski, Joseph D.. "Operationalizing COIN." Joint Special Operations University Report5, no. 2 (2005): 64.

ISAF slide of forces deployed in Afghanistan as of 5 December 2007., 2007.

Rumsfeld, Donald. "State of Afghanistan, Five Years Later." Washington Post (2006). 